\title{
REDES INTELECTUALES: INFLUENCIAS Y NOVEDADES EN LA REVISTA CRISIS, ARGENTINA: 1973-1987
}

Pablo Ponza ${ }^{38}$

RESUMEN: El objetivo general de este artículo es analizar el proyecto editorial Crisis (1973-1976, 1986-1987), observar su trayectoria y definir las diferencias que consignó en sus dos etapas. Como objetivos específicos el texto se propone, en primer término, caracterizar su posicionamiento político e ideológico, así como identificar las redes intelectuales que le permitieron constituir un prestigioso staff de colaboradores. En segundo lugar, analizar cuáles fueron sus influencias y propuestas novedosas en cuanto a contenidos. Y, por último, describir su estrategia de intervención pública, el revisionismo histórico, estético y cultural, el diálogo establecido con otras publicaciones contemporáneas, su tirada y la exitosa recepción que tuvo en el público.

Palabras clave: Redes Intelectuales; Periodismo; Crisis; Proyecto editorial; Intelectual comprometido.

ABSTRACT: The general objective of this article is to analyze Crisis as editorial project (1973-1976, 1986-1987), defining its trajectory and differences between both stages. As specific objectives is, in one hand, to analyze the political and ideological positioning of the magazine, as well as to identify the intellectual networks that made it possible to constitute a very prestigious staff of collaborators. Second, the text analyze their influences and newfangled proposals about content. Finally, describe the public intervention strategy of Crisis, specially historical and cultural revisionism, the dialogue established with other contemporary publications, his circulation and the successful reception had the project in the public of that time.

Keywords: Intellectual Networks; Journalism; Crisis; Editorial Project; Committed Intellectual.

${ }^{38}$ Doctor en Historia por la Universidad de Barcelona, Investigador Adjunto del CONICET-IDACOR-UNC y Profesor de Historia Argentina Contemporánea en la Faculta de Ciencias de la Comunicación, Universidad Nacional de Córdoba (UNC), Argentina. 


\section{Introducción}

Crisis tuvo dos épocas. En la primera alcanzó un total de 40 números a un promedio aproximado de 80 páginas por ejemplar. Comenzó su trayectoria el 3 de mayo de 1973 signada por el entusiasmo que generó el breve triunfo de la izquierda peronista en las elecciones del 11 de marzo de 1973. Y casi tres años después, el 17 de agosto de 1976, cerró sus puertas perseguida y diezmada en su staff por la acción represiva de una dictadura militar que se propuso eliminar la politización que provocaba en los espacios intelectuales y artísticos de la época. Casi 10 años después, en 1986, tras el retorno a la democracia comenzó su segunda época. Pero la prematura muerte de Federico Vogelius, su Director Ejecutivo y principal impulsor; así como las desavenencias políticas que se produjeron en el interior del colectivo editor, terminaron con la clausura definitiva de una de las más destacadas experiencias periodísticas latinoamericanas de la época.

Pero ¿cómo se constituyó el proyecto editorial Crisis?, ¿cuáles eran sus objetivos?, ¿cuál su red intelectual de pertenencia?, ¿adoptó un posicionamiento político e ideológico explícito?, ¿cuál fue su estrategia de intervención pública?, ¿cuáles sus influencias y novedades?, ¿quiénes fueron sus principales protagonistas?, y ¿qué recepción tuvo en el público? A los fines de responder estos interrogantes, comenzaremos distinguiendo dos diferentes planos de aquel tan recordado y exitoso proyecto editorial. En primera instancia, y gracias a la perspectiva que nos ofrece el paso de los años, nos detendremos en un aspecto que no parece generar dudas, que Crisis fue una revista excepcional. Algo que queda comprobado tanto en la calidad de su tratamiento editorial como en la inmediata aceptación que obtuvo en el público consumidor de esta clase de productos culturales, tan característicos de las décadas de 1960-1970. Sin embargo, por otra parte, analizaremos el carácter de sus contenidos, que no fue ni novedosa ni original, ya que su estrategia de intervención pública y el formato utilizado fue el mismo que utilizaron varias revistas que la precedieron y que le fueron contemporáneas. 


\section{Red intelectual Crisis: el proyecto editorial, sus novedades e influencias previas}

El proyecto editorial Crisis estuvo conformado por dos componentes, por un lado, la revista propiamente dicha, y por otro, Ediciones Crisis. Ambas iniciativas fueron impulsadas y financiadas por Federico Vogelius (1920-1986), quien no sólo creó y sustentó económicamente el proyecto, sino también fue quien convocó a los periodistas e intelectuales idóneos que darían curso al proyecto. Vogelius, era un acaudalado ingeniero agrónomo y abogado con un marcado costado bohemio. Fico, como le decían sus amigos, era un asiduo comprador de arte, fue mecenas de pintores y organizador de tertulias literarias. Con el correr del tiempo adquirió las colecciones de Doero, Santamarina, Carbone y Marcó del Pont, ediciones originales de escritores latinoamericanos, documentos de la época colonial, libros de viajeros y la colección etnográfica más completa de la Argentina. Con ese impresionante compendio artístico e histórico no sólo instaló una pinacoteca en San Miguel -donde fundó luego un Instituto Historiográfico-, sino que sus colecciones privadas funcionaron como fuente inédita de consulta de gran valor histórico y artístico para la revista.

Ediciones Crisis funcionó entre octubre de 1973 y agosto de 1976. Según testimonios de Julia Constenla y Aníbal Ford (SONDERÉNGUER, 2008), en sus inicios al proyecto de la editorial estuvieron vinculados Ernesto Sábato, Jorge Romero Brest, Roger Pla, Ricardo Molinari, Ernesto Epstein, Víctor Massuh, Abel Posse y la propia Julia Constenla, es decir, un grupo de intelectuales consagrados muy bien relacionados en los espacios literarios de la alta clase media letrada porteña. Ediciones Crisis se propuso publicar textos de escritores latinoamericanos con un perfil ideológico de izquierda, como Vagamundo de Eduardo Galeano, Mascaró el cazador americano de Haroldo Conti, Sota de bastos, Caballo de espadas de Héctor Tizón, entre otros. Y promocionar la biografía de personajes vinculados a grandes gestas independentistas como las de José Gervasio Artigas, Facundo Quiroga, Felipe Varela, Ernesto Che Guevara, entre otros.

Antes de ser clausurada por la violencia represiva de la última dictadura militar (1976-1983), en sus breves 35 meses de existencia Ediciones Crisis puso en marcha 5 colecciones. Según Fabián Kovacic 
(2015) Galeano aprovechó sus contactos y relaciones -además de la estupenda disponibilidad económica de Vogelius- para convocar a los mejores. Rogelio García Lupo dirigió la Colección política; el periodista chileno Alfonso Alcalde Los grandes reportajes de Crisis; su amigo Mario Benedetti Esta América -una colección dedicada a la narrativa, el ensayo y la poesía regional-. Horacio Achával, destacado editor de EUDEBA y del Centro Editor de América Latina (CEAL) se hizo cargo de una colección sin nombre. Y, finalmente, Aníbal Ford ex compañero de Galeano en la revista Che dirigió la más prolífica de estas iniciativas llamada los Cuadernos de Crisis, que publicó 29 títulos sobre diversas temáticas históricas latinoamericanas en clave revisionista. El revisionismo de Crisis fue constitutivo de su identidad, sin embargo, no vamos a detenernos en este punto ahora sino más adelante.

En cuanto a la revista, durante los 40 números de su primera época contó con 76 serigrafías creadas especialmente por 20 diferentes artistas plásticos rioplatenses como Santiago Cogorno, Daniel Zelaya, Renata Schussheim, Ana Tarsia, Ricardo Mampaey, Pablo Obelar, Raquel Palumbo, entre otros; y 50 ediciones facsimilares de fotos, periódicos, caricaturas, mapas y documentos originales ligados a la historia colonial latinoamericana, que provenían de la colección personal de Federico Vogelius. Además, su staff estaba compuesto por colaboradores de talla internacional como César Vallejo, Alejo Carpentier, Efraín Huerta, Pablo Neruda, Miguel Ángel Asturias, Gabriel García Márquez, Julio Cortázar, Mario Benedetti, Augusto Roa Bastos, Juan Gelman, David Viñas, Rodolfo Walsh, Haroldo Conti, Franciso Urondo, Osvaldo Bayer, Noé Jitrik, Jorge Rivera, Vicente Zito Lema, Heriberto Muraro, Aníbal Ford, Rogelio García Lupo, Santiago Kovadloff, María Esther Gilio, Liliana Heker, Norberto Galasso, Jorge Lafforgue, Jorge B. Rivera, Roberto Fontanarrosa, Miguel Bonasso, Raymundo Gleyzer, José Lezama Lima, entre otros. La dirección editorial era de Eduardo Galeano, la secretaría de redacción quedó bajo tutela de Julia Constenla y la diagramación a cargo del famoso Eduardo Ruccio, más conocido como Sarlanga. El rol de Galeano en la dirección editorial fue clave, no sólo por su experiencia y creatividad, sino es especial por la generosa red de contactos que había generado en toda América Latina durante sus viajes y, en especial, tras su estadía en Cuba.

Como vemos Crisis contó con tres cualidades destacadas: una amplia red de intelectuales de donde provenían los escritores- 
colaboradores, la impresionante usina documental y económica de Vogelius, y un staff con mucha experiencia. Sin embargo, como adelantamos más arriba, en términos de estrategia de intervención pública y desarrollo de contenidos no fue una revista novedosa. En este sentido, el principal mérito de la revista radicó más bien en la elaboración de una propuesta de alta calidad, de gran eficiencia comercial y logística, que logró advertir, maximizar y explotar una serie de tópicos previamente instalados.

En cuanto a los tópicos que desarrolló Crisis, cabe remitirse a dos revistas que fueron sus principales faros de influencia. Nos referimos al semanario uruguayo Marcha (1939-1974) y, en especial, a la revista cubana Casa de las Américas (1960), una publicación referencial para todo el arco literario-intelectual de la época. En ambas Galeano se desempeñó como colaborador y a través de ellas logró establecer vínculos con una importante red de escritores y periodistas latinoamericanos afines a las causas revolucionarias. Según Claudia Gilman (2003) Marcha fue pionera en la articulación de una identidad latinoamericanista, antiimperialista y tercerista, cuyas proclamas fueron tempranamente vehiculizadas por su director Carlos Quijano y, más tarde, Ángel Rama.

Por su parte, Casa de las Américas (1960) fue un rotundo éxito en los más prestigiosos y diversos círculos letrados del continente que, no sólo celebraron su aparición, sino que quisieron imitarlo. Fundada por Haydee Santamaría se definió como una publicación de letras e ideas dedicada a abordar temáticas de interés para América Latina y el Caribe con un posicionamiento deliberadamente alineado con la naciente Revolución Cubana. De hecho, el nombre completo de Crisis fue imitativo de Casa de las Américas: Ideas, letras, artes en la Crisis, aunque coloquialmente se la denominara Crisis. A través de concursos, premios y la publicación de textos, Casa de las Américas se propuso llevar a cabo la promoción de jóvenes iniciados en la creación, la investigación literaria y el pensamiento emancipador. Lo mismo que hizo Crisis una década después. La semejanza de los tópicos en ambas revistas es notable, en especial el interés por resaltar las similitudes en las experiencias estéticas y políticas, las dolencias, miserias y luchas sociales comunes a los distintos países latinoamericanos. De allí que, en el caso de Crisis, la novedad no parece haber sido la clave de su éxito, sino la maduración eficaz de temas previamente probados. 
Entre los asiduos colaboradores de Casa de las Américas estaban Gabriel García Márquez, Julio Cortázar, Mario Vargas Llosa, Ernesto Sábato, Juan Gelman, Francisco Urondo, Octavio Paz, Pablo Neruda, José María Argüedas, Rodolfo Hinostroza, Ernesto Cardenal, Roque Dalton, Manuel Pedro González, Ángel Rama, Eros Ferrán Bortolato, Bryce Echenique, José Donoso, Alberto Duque, Juan Carlos Onetti, entre otros. Es decir, muchos de los que una década más tarde -con más fama y recorrido- colaborarían con Crisis. Aunque cabe destacar que dichos autores no sólo publicaron en Casa de las Américas y Crisis sino en varias revistas de circulación continental. Este fue el caso, por ejemplo, de Siempre, Revista de la Universidad, Revista Mexicana de Literatura (México), La Bufanda del Sol (Ecuador), Amaru (Perú), Marcha (Uruguay), El Escarabajo de Oro, luego El Grillo de Papel y La Rosa Blindada, Nuevos Aires o Tiempos Modernos (Argentina), entre algunas de las publicaciones que constituyeron una red intelectual de colaboración mutua, basada en criterios de proximidad ideológica, que se consolidó a través de las revistas político-culturales, en tanto canal privilegiado de intercambio y legitimación cultural y política de la época.

Otra influencia de Crisis fue la propia obra literaria de Galeano, cuya impronta permeó fuertemente la línea editorial de la revista. Crisis reprodujo las claves del éxito obtenido por Galeano en Las venas abiertas de América Latina (1971). La estrategia del libro consistió en denunciar la cruel realidad latinoamericana mediante una revisión crítica de su proceso histórico, destacando la dominación y la violencia que devino del choque cultural entre el universo occidental eurocéntrico y el prehispánico. Tanto en Las venas abiertas de América Latina como en Crisis, Galeano intentó reseñar las matrices políticas y culturales impuestas por las metrópolis europeas en el nacimiento de los estados nacionales latinoamericanos; y lo hizo a través de la narración, el ensayo, la crónica, el uso de documentos y estadísticas. Tanto Las venas... como Crisis establecieron una relación de continuidad entre el proceso histórico y los fracasos de los proyectos independentistas puestos en marcha en el continente. Una lectura que consideró a procesos revolucionarios como el cubano en 1959 como una suerte de emergencia residual de aquellos que habían sido truncados por las oligarquías locales asociadas al imperialismo.

A partir de dichas influencias y estrategias Crisis diseñó una propuesta de alta calidad editorial enfocada en los intereses del público 
argentino, que era su público específico, y que, no sólo estaba probadamente ávido de esta clase de productos, sino que ya estaba formado y maduro en un lenguaje cuyo aparato conceptual remitía -a escala continental- a un ethos revolucionario de impronta marxistahumanista, existencialista-sartreano y cristiano post-conciliar; y -a escala local a un proyecto nacional-popular identificado con la izquierda peronista.

\section{Boom editorial, revolución, peronismo y mercado}

Crisis nunca presentó manifiestos inaugurales, sino que, con el correr de los números fue consolidando una perspectiva política e ideológica esquemáticamente identificada con la causa cubana a escala continental, y el peronismo de izquierda, a escala nacional. Esto puede advertirse, por caso, en el no 12 bajo el título "Al lector" donde se refiere a la ausencia de "manifiestos y declaraciones de principios" pero ofrece una suerte de autodefinición al postular que la revista es "un vehículo de difusión y conquista de una identidad cultural nacional y latinoamericana que quiere ser útil en el marco mayor de las luchas de liberación" (Crisis, $\mathrm{n}^{\circ}$ 12, P. 2). O como ocurrió luego en el No 18 donde indica que "el objetivo de Crisis no es el de reproducir los esquemas de las revistas literarias tradicionales (...) sino analizar los problemas de infraestructura cultural, recoger los testimonios más escondidos y marginados de la cultura popular" (Crisis, no 18, p. 4).

A diferencia de otras publicaciones argentinas de la época como Los libros o Pasado y Presente, caracterizadas por la sofisticación teórica y el lenguaje erudito, Crisis armonizó las diversas identidades de izquierda con un tono más asequible al lector no especializado. En este sentido, reprodujo hacia afuera la misma lógica de tolerancia que mostró hacia el interior de su propio colectivo editor. Según testimonio de Zito Lema, en la redacción de Crisis: "Había, claro, diferencias. Aníbal Ford seguía la línea del nacionalismo revolucionario; Juan Gelman estaba más ligado a las FAR y Montoneros; Galeano tenía un compromiso latinoamericanista; Haroldo Conti traía una lectura marxista de la realidad; y yo provenía del peronismo de base (...) parecía que nos íbamos a matar, pero había cosas profundas que nos unían, el espíritu de la época" (RUSSO, 2013, p. 4).

Crisis se estructuró internamente a partir de un artículo de investigación principal cuyo tema de actualidad se complementó con una 
entrevista a algún escritor destacado que exponía sus opiniones artísticas y políticas en un mismo plano de importancia. Luego, en torno a esos elementos se disponían el resto de los contenidos, generalmente reservado a poesías, cuentos, ensayos o documentos, donde se enfatizaron géneros considerados menores por la literatura tradicional, tales como el folletín, el circo, el teatro criollo, el grafiti, la murga, la narración oral, el radioteatro, la canción popular, los mitos y creencias de los pueblos originarios o la literatura testimonial.

Desde una matriz eminentemente literaria Crisis desbordó sobre el campo de la política, expresando no sólo una característica típica del campo intelectual de izquierda durante las décadas de 1960-1970, sino también abordando las temáticas medulares de la eclosión política que vivía la Argentina y buena parte del continente en esos años. Me refiero, en primer término, a la convergencia en la que se encontraban trabajadores, estudiantes universitarios y organizaciones político-militares durante el ciclo de movilizaciones que comenzó a escala continental con la Revolución Cubana (1959); y con el Cordobazo (1969) a escala argentina. Y, en segundo lugar, el rechazo a los regímenes militares ilegítimos y altamente represivos que se registraban en el continente.

En Argentina, hubo varias revistas que compartieron el complejo espacio peronista de izquierda, anti-imperialista y revolucionario que ocupaba Crisis. Existió incluso un diálogo tácito en la red de publicaciones que compartían el espectro militante que celebró el fin de la dictadura auto-denominada Revolución Argentina (1966-1973) y el regreso de Perón a la Argentina en junio de 1973, tras 18 años de exilio. A modo de ejemplo podemos mencionar dos casos, el de Militancia Peronista para la Liberación y Con Todo. Militancia fue dirigida por Rodolfo Ortega Peña y Luis Eduardo Duhalde, salió a la calle el 14 de junio de 1973, es decir, pocas semanas después que Crisis. Militancia logró editar 38 números antes de ser clausurada en junio de 1974. Luego pasó a llamarse De Frente, nombre con el cual no pudo evitar una nueva clausura. Con Todo ( $2^{\circ}$ época) dirigida por el sindicalista Osvaldo Villaflor, se editó desde marzo de 1974 con aparición quincenal y como publicación oficial del Peronismo de Base. Si bien Crisis, Militancia y Con Todo eran proyectos virtualmente dirigidos al mismo público, los contenidos de Militancia y Con Todo estaban enfocados con exclusividad al análisis de la coyuntura política. Su tratamiento estético era austero, esquemático y su distribución restringida a los circuitos militantes y 
sindicales afines. Por el contrario, Crisis propuso un acceso más sensorial a los contenidos políticos y explotó atribuciones de tipo técnico y artístico muy avanzados para la época, logrando una llegada más amplia y diversa gracias a su eficaz presencia en el circuito comercial.

Para dimensionar con precisión el impacto que tuvo Crisis en el mercado editorial de la época, y según cifras del Instituto Verificador de Circulaciones (IVC), en diciembre de 1972 -previo a la fundación de Crisis- en el rubro revistas Primera Plana encabezaba el ranking con una tirada de 21.266 ejemplares por número. En marzo de 1973 su más inmediata competidora, la revista Panorama, llegó a los 20.324 ejemplares por número. Ese mismo año la recién creada Crisis alcanzó una tirada promedio por número de 24.980 ejemplares, convirtiéndose en uno de los productos preferidos del público. Según relato de Julia Constenla (SONDERÉNGUER, 2008), tras los obstáculos que implicó su creación, el éxito de la revista fue inmediato. Tal es así que el primer número alcanzó una tirada de 10.000 ejemplares que se agotaron tan rápido que debieron hacer una reedición antes de sacar el segundo. "Vogelius no tenía interés en hacer un negocio con la revista. Pero tuvo mala suerte: todo lo relacionado con Crisis se vendió muy bien desde el principio" (RUSSO, 2013, p. 3). Lita Ruccio, esposa de Vogelius recuerda: "Fico me repetía cada noche: 'Encima voy a ganar plata con esta revista, la única vez que estuve dispuesto a perder guita y mirá, mirá Lita, es una maravilla” (RUSSO, 2013, p. 3).

Una de las claves del éxito comercial de Crisis estuvo en su producción y distribución. Tenía su redacción en Pueyrredón 860, Ciudad de Buenos Aires. En sus inicios fue impresa por Prensa Médica Argentina SRL; distribuida en Capital Federal por Troisi y Vaccaro, y en el interior del país por Condor SRL. En 1973 la revista podía adquirirse en puntos de venta o por suscripción a un valor de 60 pesos por año para residentes, y a 10 dólares por año para envíos a todo el Cono Sur. Según cifras publicadas por la misma revista (Crisis, $\mathrm{N}^{\circ} 18$ : 1), los promedios mensuales de circulación neta pagada consignan un ascenso sostenido. En enero de 1974 Crisis vendió 17.422 ejemplares, en febrero 16.926, en marzo 17.468, en abril 19.223, en mayo 22.093, en junio 22.919, en julio 24.637, y en agosto de 1974: 28.000 .

En mi opinión, la alta aceptación que logró Crisis tuvo su cenit en la capacidad para sintonizar las intervenciones políticas públicas emitidas desde el campo literario-cultural, coordinadamente con un mercado 
editorial en auge que, sin saberlo, estaba situado ya en la meseta previa al declive de su edad de oro. En este sentido, Matilde Sánchez (2005) ha señalado que -respecto de causas emblemáticas como la cubana y la peronista- la actuación de los escritores del llamado boom latinoamericano que colaboraban con Crisis pueden ser consideradas el punto máximo de combinación y acuerdo entre los lectores, la crítica y el mercado.

Hay que tener en cuenta que el contexto de aparición de Crisis fue signado por una inédita exuberancia de la cultura libresca, donde las revistas eran un canal privilegiado para el debate e intercambio de ideas. Recordemos que entre 1962 y los primeros años de la década 1970 la industria editorial argentina vivió una verdadera explosión. Dicha primavera editorial de estética desenfadada e imaginativa atrajo la atención de lectores de todo el planeta y generó ventas inimaginables hasta entonces. Como han señalado Hernán Invernizzi y Judith Gociol (2003), en coincidencia con la descarnada violencia política, 1974 marcó el pico máximo de dicha industria con casi 50 millones de ejemplares impresos y una tirada promedio de más de 10.000 ejemplares. Todo fue para peor a partir de entonces: 41 millones en 1975, 31 millones en 1976, 17 millones en 1979.

\section{Periodistas, historiadores, escritores: interpelar el pasado para proyectar el futuro}

Interpelar el pasado para pensar el presente y proyectar el futuro, fue quizás el acceso distintivo de Crisis. En cada número la revista ensayó una heterodoxa revisión historiográfica, no sistemática, ni cronológica de hechos del pasado que ponían en cuestión el orden político, económico y cultural del presente, para imprimir luego un horizonte de futuro revolucionario. Y si bien dicha revisión no fue original como modo de intervención pública - puesto que revistas argentinas como Cuadernos de Cultura, El Escarabajo de Oro, Cristianismo y Revolución, entre otras ya mencionadas, lo venían practicando-, el alto perfil mediático de los escritores que participaban de la revista y el modo en que introdujo la dimensión histórico-cultural en clave nacional para pensar los fenómenos estéticos logró gran convocatoria.

Tal como reseña José Luis De Diego (2001) la línea revisionista de la historia que reprodujo Crisis denunció la interpretación hegemónica de nuestra historia, que habría sido resultado de una operación fraguada por la escuela historiográfica liberal. Dicha tradición, inaugurada por figuras 
como Sarmiento y Mitre, instituyeron el paradigma dicotómico Civilización vs. Barbarie luego de la batalla de Caseros tras el exterminio de los caudillos del interior y de toda forma de cultura popular autóctona. De ese modo se habría consolidado una nueva forma de dependencia del imperialismo anglosajón representado por la oligarquía terrateniente porteña, portadora de una cultura imitativa de la europea. ¿Pero qué clase de revisionismo era el que profesaba la revista?

La reflexión crítica sobre el pasado que elaboró Crisis fue verdaderamente ecléctica, no buscó meramente poner en cuestión la veracidad de los relatos dominantes, sino exponer los contrastes con su propia perspectiva política, pertenencia ideológica e identidad cultural. Situada en las antípodas de los proyectos civilizatorios eurocéntricos, encarnó un relato historiográfico fundado en la épica peronista, a través de la cual impulsó un tratamiento alternativo de los sucesos controversiales de la historia argentina. Fue un modo de escrutar el presente de dominación económica, política, cultural -e incluso psicológica, moral y estética- que, desde su perspectiva, aparecía inscripta subterráneamente en la voz de los marginados y olvidados por los relatos cosificados de la historia oficial.

A modo de ejemplo, a continuación, presentaremos dos artículos que dan cuenta del carácter de esta línea historiográfica. En primer lugar: “Se enseña en la Argentina la historia real del país?" (Crisis, 1973, nº 8) un texto que concluye que enseñar historia plantea problemas que trascienden el campo historiográfico, pues el pasado expresa las contradicciones actuales (Crisis, 1973, n 8, p. 3). Lo llamativo de este artículo es que está compuesto por 15 autores que responden a un mismo interrogante: “ise enseña en la Argentina la historia real del país?". Entre ellos Osvaldo Bayer, autor de Severino de Giovanni el idealista de la violencia (1969), Los vengadores de la Patagonia Trágica (1971-1972), Fermín Chávez, autor de Civilización y Barbarie en la historia de la cultura argentina (1956), Vida del Chacho (1962), Vida de José Hernández (1958), Historia del país de los argentinos (1968); Arturo Jauretche, Leonardo Paso; Ana Lía Payró; Rodolfo Puiggrós; Jorge Abelardo Ramos; Vicente Sierra; José María Rosa, entre otros.

Recordemos que los mencionados, junto a Juan José Hernández Arregui, Rodolfo Ortega Peña, Juan José Real, Blas Alberti, Jorge Eneas Spilimbergo, entre otros, se identificaron con la llamada Izquierda 
Nacional, y formaron parte del colectivo de historiadores revisionistas que denunció la llamada historia oficial. En apretada síntesis podemos decir que en sus análisis expusieron las razones por las cuales los procesos revolucionarios más vigorosos no se habrían desencadenado en los países con capitalismos complejos y avanzados, sino en las colonias explotadas por las Metrópolis. Según su hipótesis los países más avanzados habían atenuado sus conflictos sociales gracias al alto desarrollo y confort conseguido mediante la esclavización y neo-colonización de Asia, África y América Latina, un argumento homólogo al de Los condenados de la Tierra de Franz Fanon, quien fue incluso más allá, proponiendo romper la espiral de dominación objetiva y subjetiva del imperialismo a través de la lucha armada, como fue el caso argelino y cubano.

El segundo ejemplo del prolífico y sistemático ejercicio revisionista de Crisis se advierte en la sección documentos, cartas, discursos del número 9 de la revista, donde se presenta a John William Cooke como un ícono nacional inmerso en las luchas populares con un pensamiento revolucionario solidario con los movimientos de liberación de América Latina, y definido como "una de las figuras más íntegras y representativas del peronismo" (Crisis, 1973, p. 3). Dicha sección presenta 6 textos de reflexión teórico-política: "La conciencia nacional es también conciencia histórica"; "La rebeldía popular y los aparatos partidarios", "Testamento", "Carta a Salvador Allende"; "Esta época de infamia"; y "La desaparición del Che Guevara”. Completan la sección 2 cartas, una escrita en 1955 desde la cárcel de Las Heras a su esposa Alicia Eguren; y una circular del Comando Superior Peronista de febrero de 1958, firmada por Perón y Cooke, cuando aún se desempañaba como representante personal de Perón en Argentina.

Trazando un paralelismo entre pasado y presente, Cooke utilizó la guerra de la Independencia de 1810 para ejemplificar lo que él considera un "caso típico de guerra subversiva, de una guerra revolucionaria que hoy quita el sueño a las minorías gobernantes y promueve las planificaciones del Pentágono”. Destaca que entonces las masas iban en contra del orden constituido y sus procedimientos eran de guerrilla, avalando la metodología cubana y la de organizaciones político-militares como Montoneros. "Ya la lucha del pueblo español fue de guerra de guerrillas. (...) Artigas era guerrillero; Güemes y sus gauchos salteños, que detuvieron el avance de los gordos, también, Boves, Páez y sus llaneros, Bolívar, Sucre, todos emplearon tácticas de guerrilla" (Crisis, 1973, p. 4). 
En resumen, esta clase de artículos expresan una sólida convicción: la historia está cambiando, la iniciativa está ahora en manos de los pueblos del Tercer Mundo. En esta clase de relatos, la tarea de Crisis aparece implícita, por un lado, destinada a denunciar la violencia descarnada de un poder aparentemente decadente. Y por otro, a insuflar de optimismo y expectativas los proyectos revolucionarios que pujaban por una transformación radical del sistema capitalista y la emancipación de la subjetividad dominada del hombre.

El evidente proceso de politización que sufrieron los núcleos intelectuales y literarios de la época indica una suerte de compulsión por intervenir en el rumbo de las decisiones de Estado. Recordemos que, a principios de la década de 1970, para muchos miembros del campo cultural de izquierda, la Argentina y Latinoamérica estaban atravesando un estadio pre-revolucionario que requería del compromiso y la expresa promoción de las convicciones, hecho que condujo con frecuencia a impulsar definiciones unívocas, donde revolucionario era considerado aquél que efectivamente se jugaba el pellejo haciendo la revolución (PONZA, 2010, p. 137). Por otra parte, advertimos que el involucramiento de intelectuales con reivindicaciones y causas políticas propias de los sectores populares, desdibujó en Crisis la tradicional imagen aristocrática del ser intelectual, invocando una auto-representación caracterizada por la rebeldía y una disconformidad urgida por definir el lugar de la acción individual en un proceso de transformación social incipiente, pero aparentemente inevitable.

En este sentido, es razonable pensar que Crisis buscó re-instalar la polémica en torno a dos conceptualizaciones antagónicas sobre cuál debía ser el rol del intelectual en el proceso revolucionario: ¿debía ser crítico u orgánico? Dicho debate, por cierto, a esa altura de los acontecimientos tampoco era novedoso, pues había superado ya su punto máximo de ebullición y decantamiento durante la llamada OLAS en Cuba, en 1967. En mi opinión Crisis reprodujo, alternativamente, ambas vertientes en paralelo. La primera de ellas representada por la del ideario de compromiso con la militancia ideológica - por utilizar las mismas palabras de Julio Cortázar en una entrevista publicada en el número 1 (Crisis, 1973, p. 17), con motivo de presentar El libro de Manuel. Y la segunda, la orgánica y vanguardista, donde la palabra y la acción revolucionaria eran parte de un mismo tándem. En este sentido, durante una entrevista realizada por Gabriel Montali (2015), Zito Lema sostiene: "nuestra 
postura era de ganar un espacio para la literatura en el mismo foco de la revolución (...) No era cuestión de escribir un panfleto; la exigencia de las formas y del estilo literario eran un desafío a llenar sin contradicción con los actos de la vida. Lo que pasa es que los actos de la vida para nuestra generación, son actos en el mismo centro de la revolución" (MONTALI, 2015).

\section{Dictadura, censura, persecución y violencia: el fin de Crisis}

Si bien ya antes del 24 de marzo de 1976 la llamada Triple A atacó ferozmente algunos miembros del staff y colaboradores de Crisis, tras el golpe de Estado la situación se agravó y comenzaron las amenazas en la redacción y los domicilios particulares. Rodolfo Walsh, Haroldo Conti, Francisco Urondo, Roberto Santoro, Raymundo Glayzer y Miguel Ángel Bustos, fueron secuestrados y aún permanecen desaparecidos. Eduardo Galeano, Juan Gelman, Vicente Zito Lema, Osvaldo Bayer, Miguel Bonasso, entre otros, se vieron forzados a vivir en la clandestinidad y finalmente optar por el exilio.

En mayo de 1976 Vogelius decidió cerrar la revista, sin embargo, no pudo evitar su secuestro, tortura y detención ilegal en 1977. Por fortuna una activa campaña de denuncia internacional encabezada por Heinrich Boll, Jorge Luis Borges y Ernesto Sábato, logró presionar al gobierno de facto para que Vogelius fuera reconocido y puesto a disposición del Poder Ejecutivo Nacional hasta 1980, año en el que recobró la libertad para exiliarse en Londres, donde comenzó acciones legales tendientes a recobrar las valiosas obras de arte que le fueron robadas de su casa, pero nunca obtuvo resultados. Según relato de Galeano, quien se encontraba entonces exiliado en Calella, Barcelona, un día Vogelius lo llamo desde Londres y le contó que los efectos de la picana eléctrica le habían aflojado los dientes de arriba y que el dentista le dijo que no era posible salvarlos. Le dijo: "Tenemos mucho de qué hablar. Desde ya quiero que sepas que no me arrepiento de nada" (Crisis, 1986, n²42, 3).

Vogelius volvió del exilio en 1985 decidido a relanzar Crisis, pero un cáncer fulminante sólo le permitió ver impreso el primer número de la segunda época. La segunda época de Crisis se desarrolló entre abril de 1986 y junio de 1987, es decir, reapareció fugazmente 10 años después de su cierre. Su director periodístico fue Vicente Zito Lema y los asesores editoriales Osvaldo Soriano y Eduardo Galeano. En la dirección de arte 
estaba Oscar Smoje, como secretario de redacción Carlos María Domínguez. En la redacción Jorge Boccanera y Claudia Pasquini; en la coordinación gráfica Regine Bergmeijer, en fotografía Julio Menajovsky y en la corrección Amalia Benedetti. Como novedad advertimos que en el staff figuran una nutrida cantidad de corresponsales en el exterior, muchos de los cuales habían participado en el primer ciclo de Crisis y aún permanecían exiliados como, por ejemplo, Miguel Bonasso en México; Eric Nepomuceno en Brasil; Alberto Pipino en Nicaragua; Osvaldo Bayer en Alemania; Tomás Eloy Martínez en Washington; Rodolfo Terragno en Londres; Mario Benedetti en Montevideo; Nora Catelli en Barcelona; Mario Paoletti en Madrid; entre otros.

Si bien tras el triunfo electoral de Raúl Alfonsín en 1983 las actividades políticas y culturales se habían reiniciado tímidamente, los efectos del Terrorismo de Estado transformaron radicalmente la relación entre cultura y política. El terror infundido por la dictadura caló hondamente en las prácticas y consumos político-culturales de la sociedad toda. La imbricación política que habían mostrado los núcleos intelectuales durante las dos décadas previas había cambiado. La derrota de los proyectos transformadores, la desaparición forzada de 30.000 personas y el exilio de más de medio millón afectaron la composición del público. La red de significaciones, creencias, gustos e intereses, así como el horizonte de futuro imaginado por los lectores no eran los mismos. Dicha transformación tuvo reflejo en los contenidos de la segunda época de la revista, por ejemplo, cuando Crisis publicó la síntesis de una serie de entrevistas bajo el título: "La juventud y la política, entre el recelo y la confianza"; donde se consultó a jóvenes entre 19 y 22 años acerca de su relación con la política y su valoración de los partidos. Los resultados revelaron el desinterés, la apatía y hasta el desprecio que reinaba entre los jóvenes frente a la militancia y los partidos políticos de izquierda. Basta recortar algunas frases del artículo para ejemplificarlo: "el proyecto de los partidos de izquierda es irrealizable, es un conjunto de utopías que no tienen en cuenta características esenciales del ser humano (...) todos tenemos algo de capitalistas (...) cuando veo los partidos acá no lo puedo creer, siguen hablando como si no hubiera pasado nada (...) eran viejos, estaban en la estratosfera, seguían hablando de cosas que ya habían pasado de moda en todo el mundo (...) la gente tiene miedo, huye de la política”. (Crisis, 1986, n 42, p. 19). 


\section{La democracia y el cambio de paradigma}

La Democracia hegemonizó el debate académico, político e ideológico durante los procesos transicionales de la década de 1980, desplazando así la centralidad que la Revolución había tenido desde fines de 1950. La promesa democrática suplantó el lugar vacante que dejó la promesa revolucionaria, una vacancia que en mi opinión habría estado motivada por diferentes razones: por la derrota política y militar, por la crisis en que estaba sumido el marxismo. Por el deseo que muchos tenían de dar vuelta de página a una historia trágica. Por el afán de eficacia a la hora de insertarse laboralmente en puestos que exigían esa transformación ideológica. Porque el contexto continental e internacional de esos años, en tanto corrientes de ideas y pensamiento político, eran favorables a los proyectos democráticos como salida a las dictaduras. Porque las instituciones académicas introdujeron gran cantidad de dineros destinados al estudio y desarrollo del pensamiento democrático, entre otras.

El ciclo inaugurado por Alfonsín en 1983 significó un verdadero cambio de paradigma. Según Gerardo Aboy Carlés (2004), una de las cualidades del discurso democrático alfonsinista fue su narrativa, construida a partir de una doble ruptura: por una parte, señaló una ruptura con el pasado reciente encarnado por la última dictadura militar y las expresiones radicalizadas de izquierda, cuya imagen fue directamente asociada a la violencia, el autoritarismo y el horror. Y por otra, confrontó ese pasado con la promesa de un futuro de pleno Estado de Derecho. Dicha narrativa tenía como finalidad desmovilizar las pasiones políticas de la sociedad, disminuir la conflictividad, así como proyectar una memoria oficial que realzara el ideal democrático.

El discurso democrático impactó plenamente en la reconfiguración de la izquierda tras la dictadura y produjo una ruptura que se asentó sobre dos grandes temas. Por un lado, el cuestionamiento a la lucha armada y la visión belicista de la política que habían aplicado tanto las organizaciones políticas como las político-militares de izquierda. Y, por otro, la revalorización de la democracia como sistema eficaz para la resolución de conflictos. El debate que generó dicha reconversión podemos observarla con nitidez en los contenidos de la segunda época de Crisis, que dejó de preocuparse por la revisión histórica de larga duración para concentrar su atención en temas de eminente coyuntura local. Para ejemplificar podemos mencionar el texto de Dante Gullo ( $\left.\mathrm{N}^{\circ} 42\right)$ titulado 
"Violentos y elitistas", donde señala la necesidad de reconocer los errores de diagnóstico y de compresión de la izquierda, errores donde a su juicio el accionar violento coadyuvó a sobre dimensionar el protagonismo de sectores elitistas que se desfasaron de la realidad y confundieron metodología con objetivos: "la crítica se puede extender más allá de la violencia. El elitismo no se manifiesta sólo en el modo de organizar la lucha armada, sino también en términos políticos, cuando el concepto de vanguardia está distanciado de la voluntad y el nivel de conciencia de las masas" (Crisis, 1986: № 42, p. 18).

Si bien hubo un sector de la intelectualidad de izquierda que hizo autocrítica, como fue el caso del llamado Club de Cultura Socialista, fundado en Buenos Aires en julio de 1984 como resultado de la fusión de dos notorios núcleos intelectuales. El primero de ellos reunido a partir de 1978 alrededor de la revista Punto de Vista, con Beatriz Sarlo, Carlos Altamirano, Hugo Vezzetti, Rafael Filippelli y Adrián Gorelik como sus miembros más visibles. Y el segundo grupo, recientemente regresado al país tras exiliarse en México, que tenía entre sus miembros a prominentes intelectuales marxistas como José Aricó, Juan Carlos Portantiero, Jorge Tula y Emilio De Ípola; hubo un sector mayoritario que siguió reivindicando la idea de Revolución, e incluso los métodos armados, y que acusó de traidores, tránsfugas y conversos a quienes buscaban re-significar positivamente la democracia. Sin embargo, era evidente que los proyectos revolucionarios que tanto vigor habían tenido en las décadas de 1960 y 1970 estaban en franca decadencia.

Con inocultable resistencia a estas ideas Crisis reflejó un costado crítico del debate político y cultural post-dictatorial. Por ejemplo, en el número 45 de agosto de 1986 "Vigencia y fragilidad del sistema democrático" de Roberto Propano y Víctor Lavagno, realizó un repaso de la paupérrima performance alcanzada por el sistema democrático en la Argentina desde Yrigoyen (1916) a Alfonsín (1983) que, a juicio de los autores, fue cíclicamente subsumida por las presiones de factores de poder tales como las corporaciones económicas, las Fuerzas Armadas e instituciones como la Iglesia. Estos tres actores fueron, sin duda, los más cuestionados durante la segunda etapa de Crisis. Por caso en el número 43 se presentó un informe especial: "La Iglesia en América latina: Religión, política y sociedad" (p. 3); en el $\mathrm{N}^{\circ} 45$ "Divorcio y autoritarismo en la sociedad argentina" (p. 18), donde Rodolfo Mattarollo describe con crudeza el rostro del poder retardatario que anidaba en la jerarquía 
eclesiástica, que enfrentó el proyecto de reglamentación del divorcio en el Código Civil.

Pero fueron las llamadas leyes de Punto Final y Obediencia Debida, la primera de ellas aprobada el 23 de diciembre de 1986, las que precipitaron las diferencias larvadas entre el colectivo editor y la familia Vogelius, heredera de la revista. Mayoritariamente para los miembros de Crisis la cuestión militar era el tema principal a debatir y resolver, pues consideraban que la democracia no podía ser construida sobre la impunidad. Sin embargo, la familia Vogelius no veía bien continuar con un perfil combativo en ese contexto político y se propuso, por el contrario, vaciar la revista de contenidos críticos. Finalmente, en una carta titulada "Adiós Crisis", Vicente Zito Lema relata el último acto de ese brillante proyecto editorial que fue Crisis. En la carta publicada en la revista Fin de Siglo (1987, n¹- Año 1, p. 2) señala que fueron las discrepancias frente a las duras críticas al Papa y las leyes de la impunidad, el llamado Punto Final y la posterior Obediencia Debida, las que obligaron a terminar con las hipocresías y dar fin al proyecto.

\section{Breve comentario final}

Auto-definida e identificada con una perspectiva latinoamericana, anti-imperialista, nacional y popular, Crisis se erigió como un proyecto editorial de gran calidad editorial e intelectual, con una organización logística capaz de dar respuestas comerciales eficientes a un ávido mercado de lectores identificados con un ideario político y cultural transformador y rebelde. Desde una matriz eminentemente literaria, el colectivo editorial desbordó sobre el campo de la política mostrándose solidario con el largo ciclo de protestas sociales que en Argentina combatieron la creciente suspensión de las actividades políticas institucionalizadas, cuya basa central había sido la marginación forzada del peronismo durante 18 años por parte de las Fuerzas Armadas.

Según inferimos, fundamentalmente en su primera etapa, Crisis intentó incorporar la figura del intelectual como sujeto clave en el proceso revolucionario a partir de dos iniciativas. En primer lugar, de su heterodoxa, pero sistemática revisión historiográfica. Y, en segundo lugar, a través de las intervenciones públicas que expresaban una ética del compromiso con el proyecto político de la izquierda peronista a nivel local y la cubana como botón de muestra a nivel continental. En este sentido, la 
estrategia puesta en acción por la revista no fue homogénea, pues reveló una trama ecléctica de colaboradores, que vivieron y expresaron la práctica política de modo diverso y a partir no sólo de sus distintas procedencias, sino también de sus diferentes estilos estético-literarios.

En cuanto a revisión historiográfica, interpeló críticamente el pasado desde un presente que vislumbraba un horizonte de futuro cuya meta final era liberarse de las diferentes formas de dominación existentes. En cuanto a la auto-representación del rol de los intelectuales, sus intervenciones no impulsaron un ideario o categorización taxativa y unívoca sino, más bien, dos grandes conceptualizaciones -la del crítico y el orgánico- en tanto reflejó de la heterogeneidad de voces que habitaron el colectivo editor. Aunque, cabe decir, que en ambos casos los hacedores de Crisis expresaron el paradójico y peligroso intento de ligar el mundo de la cultura con el de la política y el del pensamiento con el de la acción.

\section{BIBLIOGRAFÍA}

ABOY CARLÉS, Gerardo. Las dos Fronteras de La democracia Argentina. Buenos Aires: Homo Sapiens, 2001.

ABOY CARLÉS, Gerardo. Parque Norte o la doble ruptura alfonsinista. En: Marcos NOVARO (Comps.). La historia reciente. Argentina en democracia. Buenos Aires: Edhasa, 2004.

ALTAMIRANO, Carlos. Peronismo y cultura de izquierdas. Buenos Aires: Siglo XXI, 2011

ALtAMIRANO, Carlos. Bajo el signo de las masas. Buenos Aires: Aries, 2001

BADIOU, Alan. El siglo. Buenos Aires: Manantial, 2005

BASCHETTI, Roberto. Documentos 1970-1973. Vol.1. Buenos Aires: Campana de Palo, 2004.

BASCHETTI, Roberto. "Una interrelación entre Periodismo e Historia Política Argentina". Universidad Nacional de La Plata, Facultad de Periodismo y Comunicación Social. Conferencia, 2000.

CRISIS, desde año 1, Número 1, mayo 1973, hasta año 3, Número 40, agosto 1976.

DE DIEGO, José Luis. "El proyecto ideológico de Crisis". En Prismas, revista de historia intelectual, $n^{\circ}$ 5, 2001: 127-141. 
Fin de Siglo. Año 1, Número 1. Buenos Aires, 1987.

GILMAN, Claudia. Entre la pluma y el fusil. Buenos Aires: Siglo XXI, 2003.

GIUNTA, Andrea. Vanguardia, Internacionalismo y Política. Buenos Aires: Siglo XXI, 2008.

INVERNIZZ, Hernán y GOCIOL, Judith. Un golpe a los libros. Buenos Aires: Eudeba, 2003.

KOVACIK, Fabián. Galeano. Apuntes para una biografía. Buenos Aires: Ediciones B, 2015.

PONZA, Pablo. 2010. Intelectuales y violencia política: 1955-1973. Córdoba: Babel.

RUSSO, Miguel. "La revista Crisis y la busca del tiempo perdido". 14/04/2015. http://www.nodalcultura.am/2015/04/los-trabajosde-galeano-la-inolvidable-revista-crisis/ 2015, Consultada el 01/01/2017.

RUSSO, Miguel. "La revista Crisis y la búsqueda del tiempo perdido», disponible en internet en http://www.contrainfo.com/9894/larevista-crisis-y-la-busca-del-tiempoperdido/ 2013, consultada el 01/12/2016.

SÁNCHEZ, Matilde. Un linaje de Brillantes novelistas. Buenos Aires: Clarin, 28/08/2005: 106.

SÁNCHEZ MORENO, Diego Alberto. Reseña de "Las venas abiertas de América Latina" de Eduardo Galeano. En-claves del Pensamiento, vol. I, $n^{\circ} 1$, junio 2007: 203-206.

SONDERÉNGUER, María. Revista Crisis (1973-1976). Del intelectual comprometido al intelectual revolucionario. Bernal: Universidad Nacional de Quilmes, 2008.

TORTTI, María Cristina. "Protesta social y Nueva Izquierda en la Argentina del Gran Acuerdo Nacional”. pp. 205-230. En Pucciarelli, Alfredo. La primacía de la política. Buenos Aires: Eudeba, 1999.

TARCUS, Horacio. Introducción al catálogo de revistas culturales argentinas. Buenos Aires: Cedinci, 2007.

ZITO LEMA, Vicente. Entrevista realizada por Gabriel Montali: Adiós Mundo Cruel, Radio Nacional Córdoba, 24/02/2013.

Recebido em: 10/07/2018

Aceito em: 26/07/2018 